\title{
Ablation of supraventricular tachycardia in children using a limited fluoroscopy approach with the electro-anatomical system guidance
}

\section{Çocuklarda elektroanatomik haritalama eşliğinde sınırlı floroskopi ile supraventriküler taşikardilerin ablasyonu}

\author{
Özlem ELKIRAN ${ }^{1} \oplus$, Celal AKDENiZ ${ }^{2} \oplus$, Volkan TUZCU $^{2} \oplus$
}

\section{ABSTRACT}

\begin{abstract}
Aim: Athough, catheter ablation has become established therapy for treatment of pediatric SVT, X-ray has been used during electrophysiological procedures. Recent advances in electroanatomic mapping technologies resulted in a decrease or elimination of fluoroscopy during catheter ablation. Although, radiofrequency ablation (RFA) is a common option for treatment of tachyarrhythmias, it has irreversible risk of AV block. Cryoablation is preferred for septal tachycardia substrates due its safety. In this study, we presented our results of children who underwent SVT ablation using electroanatomical system and experiences in cryoablation.
\end{abstract}

Method: A total of 48 children underwent ablation of SVT. All procedures were performed using the EnSite System (St. Jude Medical, Inc., St. Paul, $M N, U S A)$.

Results: Thirty patients had AVNRT, one of these had an additional atrial tachycardia and the other one had atypical AVRNT, 7 had concealed AP, 9 had manifest AP, 2 had atrial tachycardia, and one had Mahaim AP. Fluoroscopy was not used in 42 patients (87.5\%). The mean fluoroscopy time in the remaining $6(12.5 \%)$ patients was $6.0 \pm 2.28$ minutes.Cryoablation was used in $34(70.8 \%)$ and RFA in $14(29.2 \%)$. Acute success was 9A5.8\%. During follow-up of duration, SVT recurred in 3 patients (6.2\%). These patients underwent second successful ablation procedures. Final success was $100 \%$. No permanent AV block was observed. An uneventful pericardial needle injury occured in one patient during transseptal puncture with minimal effusion.

Conclusions: Catheter ablation of SVT can be performed effectively with limited fluoroscopy approach. Cryoablation should be preferred for ablation of septal tachycardia substrates, including AVNRT.

Keywords: Catheter ablation, supraventricular tachycardia, children, limited fluoroscopy, three dimentional mapping öz

\begin{abstract}
Amaç: Çocuklarda supraventriküler taşikardi (SVT)'lerin tedavisinde kateter ablasyon başarılı olarak uygulanmakla birlikte, geleneksel yöntemle yapılan ablasyon işlemlerinde X-ışıları kullanılmaktadır. Son dönemlerde, elektroanatomik haritalama sistemlerinin geliststirilmesi ile ablasyon işlemlerindeki floroskopi maruziyeti azaltılmıș, hatta bazı ișlemlerde tamamen elimine edilmiştir. Radyofrekans ablasyon (RFA) taşiaritmilerin tedavisinde yaygın olarak kullanılan bir yöntemdir. Ancak, atriyoventriküler (AV) tam blok riski taşımaktadır. Bu nedenle son dönemlerde atriyoventriküler nodal reenteran taşikardi (AVNRT)'yi de içeren septal taşikardi substratlarında kriyoablasyon (KRA) yeğlenmektedir. Bu çalışmada, elektroanatomik haritama kullanılarak SVT ablasyonu yapılan hastalarımız ve kriyoablasyon deneyimlerimiz sunulmuştur.
\end{abstract}

Yöntem: SVT nedeniyle kliniğimizde elektrofizyolojik çalıșma yapılan 48 çocuk retrospektif olarak değerlendirildi. Tüm prosedürler Ensite NavX Sistem (St. Jude Medical, St. Paul, MN,USA) eşliğinde yapıldı.

\begin{abstract}
Bulgular: Otuz hastada AVNRT, bu hastaların birinde atriyal taşikardi (AT) vardı, diğer bir hastada tipik ve atipik AVNRT birlikteydi. Yedi hastada gizli $A P, 9$ 'unda manifest AP, 2'sinde sağ taraflı AT, bir hastada Mahaim AP vardı. Kırk iki $(\% 87,5)$ hastada hiç floroskopi kullanılmadı. Geriye kalan $6(\% 12,5)$ hastada ortalama floroskopi süresi 6,0 2,28 dk. (medyan: 6.0; aralık: 3-10 dk.) idi. Otuz dört $(\% 70,8)$ hastada KRA, $14(\% 29,2)$ hastada RFA uygulandı. Akut başarı $\% 95,8$ oranındaydı. 16 $\pm 10,02$ aylık izlem süresinde $3(\% 6,2)$ hastada nüks görüldü. Bu hastalara 2. seansta başarılı ablasyon yapıldı. Uzun süreli izlemde bașarı oranı \%100 idi. Hiçbir hastada kalıcı AV tam blok gelişmedi. Bir hastada transseptal girişim sırasında perikardiyal boyanma ve minimal perikardiyal efüzyon dışında komplikasyon olmadı.
\end{abstract}

Sonuç: Çocuklarda SVT ablasyonu elektroanatomik haritama yöntemiyle ve sınırlı floroskopi ile başarı ile uygulanabilir. AVNRT ve septal taşikardi substratlarında KRA yeğlenmelidir.

Anahtar kelimeler: Kateter ablasyon, supraventriküler taşikardi, çocuk, sınırlı floroskopi, üç boyutlu haritalama

Received: 02.09.2018

Accepted: 10.10 .2018

${ }^{1}$ Department of Pediatric Cardiology, Faculty of Medicine, Inonu University, Malatya, Turkey

${ }^{2}$ Department of Pediatric Cardiology/Electrophysiology, Istanbul Medipol University Hospital, Istanbul, Turkey

Corresponding author: Özlem Elkıran, Department of Pediatric Cardiology, Faculty of Medicine, Inonu University, Malatya, Turkey

e-mail: ozlemelkiran@yahoo.com

ORCID ID's:

Ö.E. 0000-0002-6855-0346, C.A. 0000-0002-8647-6055, V.T. 0000-0001-9008-4997 


\section{Giriş}

Supraventriküler taşikardiler (SVT) çocukluk döneminde sık görülen kardiyak ritm bozukluklarındandır. Sıklığı 1/250-1/1000 arasında bildirilmiştir ${ }^{1}$. Çoğunluğunun nedeni bilinmemekle birlikte, yapısal kalp hastalıkları varlığında da görülebilir. SVT mekanizması yaşla değişiklik gösterir. Atriyoventriküler reenteran taşikardi (AVRT) bebek ve küçük çocuklarda, atriyoventriküler nodal reenteran taşikardi (AVNRT) ise büyük çocuklarda daha sık görülmektedir. SVT'in büyük çoğunluğu aksesuar yola sekonder gelişir. Bu olguların da yaklaşık \%30'u bir yaşından sonra düzelir. SVT'li çocukların yaklaşik \%50'si ilk ataklarını yaşamın ilk yıIında yaşar. Erken çocukluk döneminde (6-9 yaş) SVT insidansında ikinci bir artış ve daha sonra adolesan dönemde yine bir artış görülür ${ }^{1-4}$.

Kateter ablasyon çocukluk dönemindeki SVT'lerin tedavisinde 1990 yıllardan bu yana kullanılmaktadır. Çocuklarda ilk kateter ablasyon uygulamasından bu yana, ablasyon endikasyonları medikal tedaviye dirençli aritmilerden, ilk tercih tedavi olmaya doğru kademeli olarak değişmiştir. Günümüzde supraventriküler taşikardilerin tedavisinde kateter ablasyon işlemi çocuklarda güvenli ve etkili bir yöntem olarak kullanılmaktadır ${ }^{5,6}$. Bununla birlikte, konvansiyonel ablasyon işlemleri $X$ ışını kullanılarak, floroskopi altında yapıldığından hem hastalar hem de işlemi uygulayan sağılık personeli uzun dönemde yüksek miktarda radyasyona maruz kalmaktadır. Medikal işlemler sırasında iyonize radyasyona maruz kalmanın dermatit, katarakt, tiroid hastalığı, doğumsal defektler ve malignite ile ilişkili olduğu bilinmektedir. Özellikle çocuklarda uzun yaşam beklentisi nedeniyle kümülatif radyasyon maruziyetinin etkileri erişkinlerden daha fazladır ${ }^{7-9}$.

Son yıllarda, modern üç boyutlu (3-D) elektroanatomik haritalama sistemlerinin kullanılması ile ablasyon işlemleri sırasında kullanılan floroskopi süreleri önemli düzeyde azaltılmış hatta bazı işlemlerde tamamen elimine edilmiştir. Ablasyon işlemleri sırasında 3-D haritalamanın kullanımı yalnızca radyasyon maruziyetini azaltmakla ya da ortadan kaldırmakla kalmaz, aynı hedef noktaya etkili lezyonların oluşturulmasına olanak sağlayarak, başarı oranlarını da belirgin olarak arttırır. Üç boyutlu haritamala eşliğinde yapılan ablasyon ile başarı oranı giderek artmış ve aritmi tipi ve aritmik odağın lokalizasyonuna göre \%95-100 oranında rapor edilmiştir. Rekürrens oranı \%2-8 arasında bildirilmiştir, komplikasyon ise oldukça nadirdir ${ }^{10-12}$.

Radyofrekans ablasyon (RFA) aritmilerin tedavisinde uzun süredir yaygın olarak kullanılan, başarı oranı yüksek bir yöntemdir. Ancak, RFA ile AV tam blok riski önemli bir sorun olmaya devam etmektedir ${ }^{13,14}$. Kriyoterapi, ablasyon tedavisinde daha yeni bir yöntem olup, özellikle AVNRT, AV nod veya his demetine yakın aksesuar yol (AP) ablasyonlarda yeğlenmektedir. Kriyoenerjinin kardiyak dokuda eksi $30^{\circ} \mathrm{C}$ 'de geri dönüşümlü etki oluşturarak, ablasyon etkisini değerlendirme özelliği kriyo-haritalama olarak adlandırılmaktadır ve bu özellik kriyoablasyonun önemli bir avantajıdır. Literatürde kriyoablasyon (KRA) ile AV tam blok bildirilmemiştir. KRA'un sağladığı bir diğer yarar, kateterin endokarda yapışması nedeniyle kateter stabilizasyonunu kolaylaştırmasıdır. Bu özellik sayesinde ablasyon işlemi sırasında floroskopi gereksinimi azalmakta ve ablasyon sırasında iletim dokusunun hasar görüp görmediği değerlendirilebilmektedir ${ }^{15,16}$.

Bu çalışmada, merkezimizde 3-D haritama yöntemi EnSite-NavX Sistem (St. Jude Medical, St. Paul, MN,USA) kullanılarak sınırlı floroskopi ile SVT ablasyonu yapılan hastalar ve sonuçları sunulmuştur. Ek olarak, KRA uygulanan hastalarımızdaki deneyimlerimiz bildirilmiştir.

\section{GEREÇ ve YÖNTEM}

\section{Hasta özellikleri}

Bu çalışmada, Çocuk Kardiyoloji Kliniğinde Kasım 2016-Mayıs 2018 tarihleri arasında SVT nedeniyle elektrofizyolojik çalışma ve ablasyon işlemi yapılan olgular retrospektif olarak değerlendirildi. Çalışma öncesinde yerel Etik Kuruldan onam alındı. (Etik kurul numarası: 2018/03.) Çarpıntı atağı elektrokardiyogram (EKG), 24-saatlik holter EKG veya event recorder ile dökümante edilen toplam 48 hasta $\left(25^{\prime} \mathrm{i}\right.$ 
Tablo 1. Hastaların demografik ve klinik karakteristikler.

\begin{tabular}{ll}
\hline & $\mathbf{n}=\mathbf{4 8}$ \\
\hline Yaş (yıl) & $13,88 \pm 3,2$ \\
Cinsiyet (E/K) & $25 / 23$ \\
Ağırlık & $51,18 \pm 14,37$ \\
Boy & $156,24 \pm 15,43$ \\
Kalp hastalığı & \\
$\quad$ Kalp hastalığı yok & $45(\% 94)$ \\
$\quad$ Opere ASD & $1(\% 2)$ \\
$\quad$ MY & $1(\% 2)$ \\
Servikal aortik ark & $1(\% 2)$ \\
Aritmi substratları & \\
$\quad$ AVNRT* & $30(\% 62)$ \\
Gizli AP & $7(\% 14)$ \\
Manifest AP (WPW sendromu) & $9(\% 18)$ \\
AT* & $2(\% 4)$ \\
Mahaim AP & $1(\% 2)$ \\
\end{tabular}

Veriler ortalama土standart sapma, ağırlık $(\mathrm{kg})$, boy $(\mathrm{cm})$ gösterildi.

* Bir hastada AVNRT ve AT birlikteydi. Erkek:E, KIz:K; ASD: Atriyal septal defekt, MY: Mitral yetmezliği, AVNRT: Atriyoventriküler nodal reenteran taşikardi; AP: Aksesuar yol; AT: Atriyal taşikardi

erkek, 23'ü kız) çalışmaya alındı. Tüm hastaların işlem öncesi 12 kanal EKG, holter ve ekokardiyografik değerlendirmeleri yapıldı. Hastaların demografik ve klinik özellikleri, prosedür detayları ve izlem sonuçları kaydedildi.

\section{Elektrofizyolojik Çalışma ve Ablasyon İşlemleri}

İşlem öncesi hasta ve/veya ebevenlerden bilgilendirilmiş onam formu alındı. Elektrofizyoloji işlemleri hastanın yaşına bağlı olarak lokal anestezi ve hafif sedasyon eşliğinde ya da genel anestezi altında yapıldı. Venöz erişim bilateral femoral venler ile sağlandı. Antiaritmik ilaçlar elektrofizyolojik çalışmadan enaz beş yarılanma ömrü öncesinde kesildi. Tüm elektrofizyolojik çalışma ve ablasyon işlemleri Ensite NavX Sistem (St. Jude Medical, St. Paul, MN, USA) eşliğinde yapıldı. Üç boyutlu olarak, floroskopi kullanılmadan sağ atriyum haritası çıkarıldıktan sonra, elektroanatomik haritalama eşliğinde kateterler sağ atriyum, koroner sinus ve sağ ventrikül apeksine yerleştirildi. Taşikardi mekanizmasını ve aritmi odağını saptamak için standart elektriksel uyarım (pacing) protokolleri ve haritalama kullanıldı. Standart pacing ile taşikardi indüklenemeyen hastalara orcipirenalin (Alupent ${ }^{\circledR}$ )
Tablo 2. İşlem karakteristikleri ve ablasyon sonuçları.

\begin{tabular}{ll}
\hline & $\mathrm{n}=\mathbf{4 8}$ \\
\hline İşlem süresi (dk.) & $136 \pm 32,7$ \\
Fluoroskopi süresi* (dk.) & $6,0 \pm 2,28$ (medyan: 6,0) \\
RF ablasyon (\%) & $14(30)$ \\
Kriyoablasyon (\%) & $34(70)$ \\
Akut başarı oranı (\%) & 95,80 \\
İzlem süresi (ay) & $16 \pm 10,02$ \\
İzlemde rekürrens oranı, $\mathrm{n}(\%)$ & $3(6,20)$ \\
Uzun dönem başarı oranı, $\mathrm{n}(\%)$ & $48(100)$ \\
& \\
\hline
\end{tabular}

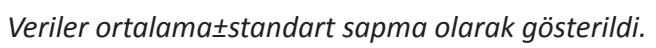

* $n=6$ hasta; dk.: Dakika; RF: Radyofrekans

intravenöz (IV) uygulandı. Sol taraflı aksesuar yolu olan hastalarda varsa patent foramen ovale yoluyla, değilse transseptal yaklaşımda sol atriyuma geçildi. Sol tarafa geçilen olgularda, sol atriyumda kateterin olduğu netleştirildikten sonra heparin 50-100 ünite/ kg IV uygulandı.

\section{Ablasyon Prosedürleri}

Standart elektrofizyolojik çalışma sonrası radyofrekans ablasyon işlemleri operatörün yeğlemesine göre irrigated veya non-irrigatted $4 \mathrm{~mm}$ uçlu radyofrekans (RF) ablasyon kateteri ile yapıldı. RFA sırasında devamlı olarak ısı ve impedans kontrolü sağlandı. Radyofrekans enerji, non-irrigated RF kateteri ile hedef ISI $60^{\circ} \mathrm{C}$ ve power $30-50$ watt, irrigated $\mathrm{RF}$ kateteri ile $40^{\circ} \mathrm{C}$ ve power $30-40$ watt olacak şekilde maximum 60 sn süreyle uygulandı. Tüm AVNRT olgularında ve AV noda yakın taşikardi odaklaklarında KRA uygulandı. KRA işlemleri 7F $6 \mathrm{~mm}$ veya $9 \mathrm{~F} 8 \mathrm{~mm}$ uçlu ablasyon kateterleri (Medtronic, Minneapolis, MN) kullanılarak yapıldı. Kriyokateter boyutunun tercihi hasta yaş ve kilosu ( $8 \mathrm{~mm}$ uçlu kateter $>12$ yaş ve $>35 \mathrm{~kg}$ ) ve operatörün tercihine göre belirlendi. Altı $\mathrm{mm}$ uçlu kateter kullanıldığında, eksi $30^{\circ} \mathrm{C}$ 'de kriyo-haritalama ile ablasyona başlandı. Sekiz $\mathrm{mm}$ uçlu kateter kullanıldığında ise daha önce belirlenen hedef noktaya 30 sn'yi aşmayan test lezyonları verildi. AVNRT ablasyonunda, kriyoharitalama ya da kriyotest lezyonları anatomik yavaş yol bölgesinin olduğu alana uygulandı. Kriyolezyonlar eğer mümkünse 
taşikardi sırasında, değilse normal sinüs ritminde verildi. Kriyo-haritalama veya test lezyonu ile başarılı olunan bölgede lezyona devam edilerek, uygun sayıda lezyon tamamlandı. En son yapılan başarılı ablasyon işlemi sonrası yarım saatlik beklemenin ardından programlı stimülasyon ile ve orciprenalin uygulaması sonrası taşikardinin indüklenememesi durumunda işlem başarılı olarak kabul edildi.

\section{İzlem}

Tüm hastalar işlem sonrası 24 saat izlendi. Tüm hastalara taburculuk öncesi fizik muayene, 12 kanal EKG ve gerekli olan hastalara 24 saatlik Holter monitörizasyonu ve ekokardiyografi yapıldı. Hastalar işlem sonrası 2. hafta, 3. ay ve 6 . ayda ve daha sonra yıllık olarak değerlendirildi. Ablasyon öncesindeki SVT ile uyumlu çarpıntı ataklarının olması, taşikardinin veya preeksitasyonun 12 kanal EKG, 24 saatlik holter monitörizasyonu ve event recorder ile yine belirlenmesi nüks olarak değerlendirildi.

\section{İstatistiksel analiz}

Verilerin istatistiksel değerlendirilmesinde SPSS Windows 25,0 paket programı kullanıldı. Niceliksel değişkenler ortalamaıstandard sapma, kategorik değişkenler yüzde ya da normal dağılıma uymayan söylemler ortanca ve çeyrek sapma olarak belirtildi.

\section{BULGULAR}

\section{Hasta Özellikleri}

Tablo 1'de hastaların demografik ve klinik özellikleri gösterilmiştir. İşlem sırasında hastaların ortalama yaş ve kilosu sırasıyla $13,88 \pm 3,20$ yıl $(7,44-18,2$ yıl) ve $51,18 \pm 14,37 \mathrm{~kg}$ idi. Bir hastada SVT ye ek olarak bir olguda opere atriyal septal defekt, bir diğer olguda da romatizmal ateşe ikincil gelişen birinci derece mitral yetersizlik, diğer bir olguda da servikal aortik ark mevcuttu. Aritmi substratlarına bakıldığında 30 hasta AVNRT (bazı olgularda birden fazla substrat mevcuttu) vardı (bu olguların birinde sağ atriyum posterior kaynaklı atriyal taşikardi (AT), diğer bir olguda atipik ve tipik AVNRT birlikte saptandı). Yedi olguda gizli AP (6 olgu sol taraf, 1 olgu sağ taraf), 9 olguda manifest AP (5 olgu sağ taraf, 4 olgu sol taraflı), 2 olguda sağ taraflı AT, bir olguda atriyofasiküler (Mahaim) AP vardı.

\section{İşlem özellikleri ve ablasyon başarısı}

Hastaların işlem karakteristikleri Tablo 2'de gösterilmiştir. Standart elektrofizyolojik çalışma sonrası, işlemlerin 34'üne KRA $(\% 70,80)$ ve 14 'ine RFA $(\% 29,20)$ uygulandı. Akut başarı \%95,8 oranındaydı. ìki olguda işlem başarısız oldu. Bunlardan sol lateral gizli AP li olan olguda transseptal işlemi yapılırken perikardda boyanma ve spontan gerileyen minimal perikardiyal efüzyon nedeniyle işlem sonlandırıldı, ikinci seansta başarılı ablasyon uygulandı. Epikardiyal yerleşimli sol posterolateral manifest AP olan bir olguda ise ikinci seansta irrigasyonlu RF ile başarılı ablasyon yapıldı. Toplam işlem süresi $136 \pm 32,70$ dakika (dk.) idi. Floroskopi $42(\% 87,5)$ işlemde hiç kullanılmadı.

\section{Komplikasyonlar}

Dört hastada 1. AV blok, iki hastada inkomplet sağ dal bloğu olmak üzere toplam altı $(\% 12,5)$ olguda prosedür sırasında çeşitli derecelerde AV blok gelişti. Bloklar, işlem bitmeden saniye-dakikalar içinde tamamen normale döndü. Hiçbir olguda kalıcı AV tam blok gelişmedi ve ek major komplikasyon görülmedi. Bir olguda transseptal iğne girişi sırasında kontrastla minimal perikardiyal boyanma nedeniyle, işlem ertelendi. íkinci seansta başarılı ablasyon işlemi uygulandı.

\section{İzlem}

Toplam 16 $\pm 10,02(1,22-32,49)$ aylık izlem süresinde hiçbir olgu takipten çıkmadı. İzlemde 3 olguda nüks görüldü $(\% 6,2)$. Bu olgulardan birinde sağ anterolateral gizli $A P$, diğerinde sol lateral gizli $A P$, birinde tipik AVNRT vardı. Bu olgulara 2. seansta başarılı ablasyon yapıldı. Uzun süreli izlemde başarı oranı \%100 idi.

\section{TARTIŞMA}

Çocukluk çağı SVT'lerinde medikal tedavi hasta ve aile 
uyumunu gerektirir ve tedavide kullanılan antiaritmik ilaçların aynı zamanda proaritmik etkileri de vardır. Bu nedenle uygun vakalarda ablasyon tedavisi günümüzde ilk seçenek haline gelmiştir ${ }^{5,6}$. Bununla birlikte, elektrofizyoloji ve ablasyon işlemleri sırasında kullanılan X ışınları geleneksel yöntemle yapılan ablasyon işlemlerinin önemli dezavantajlarındandır. Pekçok çalışmada iyonize radyasyonun vücuttaki farklı dokulara zararlı etkileri net olarak gösterilmiştir. Daha önemlisi çocuklar uzun yaşam beklentisi nedeniyle iyonize radyasyonun karsinojenik etkisine çok daha duyarlıdır. Ayrıca bu işlemler sırasında, işlemi yapan sağlık personeli de uzun dönemde yüksek miktarda iyonize radyasyona maruz kalmaktadır. Ancak, son yıllarda elektroanatomik haritalama sistemlerinin kullanılması ile floroskopi süresi belirgin olarak azaltılması hatta bazı işlemlerde tamamen elimine edilmesi olası olmuştur ${ }^{7-10}$. Tuzcu ${ }^{17}$, çalışmasında ablasyon işlemlerinde 3-D haritalama ile etkinlik ve güvenilirlikten ödün vermeden floroskopi sürelerinde önemli azalma hatta eliminasyon sağladığını bildirmiştir. Smith ve Clark ${ }^{18}$ da benzer şekilde 3-D haritalama eşliğinde yaptıkları ablasyon işlemlerinde floroskopiyi \%95 oranında azalttıklarını ve olgularının önemli bir kısmında hiç floroskopi kullanmadıklarını rapor etmişlerdir. Swissa ve ark. ${ }^{10 \prime}$ nın çalışmasında da, AVNRT ablasyonunda klasik floroskopik yöntemle, 3-D haritama yöntemini karşılaştırmış ve 3-D elektroanatomik haritalama ile floroskopi süresinde önemli azalma sağladıklarını bildirmişlerdir. Çalışmamızda da, hastalarımızın büyük çoğunluğunda $(\% 87,5)$ floroskopi kullanılmadı. Floroskopi yalnızca transseptal girişim sırasında ya da nadiren kateter pozisyonunun belirlenmesinde sınırlı olarak kullanıldı. Floroskopi gereken 6 olguda ortalama floroskopi süresi $6 \pm 2,80 \mathrm{dk}$ (3-10) idi.

Radyofrekans ablasyon yöntemi hem çocuk hem de erişkinlerde supraventriküler taşikardilerin ablasyonunda güvenli ve etkili bir yöntem olmakla birlikte, RFA ile AV tam blok riski elektrofizyologlar için önemli bir sorun olmaya devam etmektedir. Özellikle AVNRT veya AV nod ya da his demetine yakın AP ablasyonlarda AV tam blok riski azımsanmayacak orandadır. AVNRT ablasyonunda bu risk \%1-3 oranında, septal ve anteroseptal AP ablasyonlarında ise \%2-10 oranında bildirilmiştir ${ }^{14}$. Çocuk hastalarda AV tam blok riski hasta ve ailesi için daha da travmatiktir. RF ablasyon sırasında düşük enerji kullanımı daha az AV blok riski taşımakla birlikte, rekürrens oranlarını da arttırmaktadır ${ }^{19}$. Buna karşın, çeşitli çalışmalarda kriyoablasyon (KRA) sırasında \%2-23 oranında AV nod irritasyonuna bağlı değişik derecelerde geçici AV blok bildirilmiş olmakla birlikte, kalıcı AV tam blok bildirilmemiştir. Bu nedenle KRA günümüzde uygun vakalarda artan oranlarda yeğlenmektedir. Bastani ve ark. ${ }^{20}$ çalışmalarında olguların \%26'sında AV blok riski nedeniyle KRA yeğlediklerini bildirmişlerdir. Benzer şekilde Ergül ve ark. ${ }^{11}$ da olgularının \%29'unda yüksek AV blok riski nedeniyle KRA yeğlediklerini rapor etmişlerdir. RF ablasyon yönteminin bir diğer istenmeyen yönü ağrılı olması, tromboembolik olay, kardiyak perforasyon ve koroner arter zedelenmesi riski taşımasıdır. Buna karşın, KRA ağrısızdır ve daha az tromboembolik olay riski taşımaktadır. Bu nedenle işlem sırasında hasta konforu daha iyidir ve operator stresini de azaltmaktadır. KRA'un ağrısız olması nedeniyle olgularda anestezi gereksinimi da azalmaktadır. KRA sırasında donma etkisi ile kateterin endokarda yapışması kateter stabilizasyonu sağlamaktadır. Bu nedenle kateter stabilizasyonunun zor olduğu bölgelerde de KRA tercih edilen bir yöntem haline gelmiştir ${ }^{21,22}$. Ergül ve ark. ${ }^{11}$ 'nın çalışmasında, 3-D haritalama eşliğinde KRA yaptıkları anteroseptal AP'li olgularda akut başarı oranı $\% 95,8$ ve nüks oranı $\% 8,7$ olarak olarak bildirilmiştir. Nüks olan olgulara 2. seansta başarılı KRA yapılmış ve uzun dönemli başarı oranı \%100 olarak saptanmıştır. Bu çalışmada, yanlızca bir olguda geçici AV blok dışında komplikasyon olmadığı bildirilmiş ve anteroseptal AP'li olgularda KRA'un etkili ve güvenilir olarak kullanılabileceği sonucuna varılmıştır. Çalışmamızda da, tüm AVNRT'li olgularda ve AV tam blok riski olan bölgelerde KRA yöntemi uygulandı. Çalışmamızda, akut başarını oranı \%95,8 idi ve $6(\% 12,5)$ olguda işlem sırasında değişik derecelerde geçici AV blok oluşmasına rağmen, KRA işleminin durdurulmasının takip eden saniye-dakikalar içinde blok düzeldi. Hiçbir olguda kalıcı AV tam blok gelişmedi.

Kriyoablasyon yönteminin kullanılmaya başlamasından sonra artan klinik deneyimler ve daha geniş uçlu katererlerin kullanımı ile birlikte akut başarı oranları 
da giderek artmıştır. Kriyokateter ile yapılan ilk ablasyonlarda akut başarı oranları yalnızca \%69-92 arasında iken, son dönemlerde \%83-100 arasında rapor edilmiştir $^{22-24}$. Pediatrik vakalarda da KRA ile ilk deneyimlerde yüksek nüks oranları bildirilmekle (\%7-20) birlikte, daha sonraki yıllarda $6 \mathrm{~mm}$ ve $8 \mathrm{~mm}$ uçlu kriyokateterlerin kullanıma girmesi ile nüks oranları da belirgin oranda azalmıştı ${ }^{25,26}$. Çocuklarda AVNRT de KRA'unun değerlendirildiği çok merkezli bir çalışmada, $6 \mathrm{~mm}$ ve $8 \mathrm{~mm}$ uçlu kriyokateter ile $4 \mathrm{~mm}$ uçlu kateter ile karşılaştırıldığında daha yüksek başarı ve daha düşük nüks oranları saptanmıştır ${ }^{27}$. Chanani ve ark. ${ }^{28}, 4$ $\mathrm{mm}$ uçlu kriyokateterle nüks oranını \%18 iken, $6 \mathrm{~mm}$ uçlu kriyokateterle \%9 olarak bildirmişlerdir. McDaniel ve ark. ${ }^{29}$ KRA ile nüks oranını $\% 5$ olarak bildirmişler ve nüksün en önemli belirleyicisinin $<4$ dakikanın altında lezyon vermek ve $<6 \mathrm{~mm}$ kateter kullanmak olduğunu saptamışlardır. Tuzcu ve ark. ${ }^{30}$ AVNRT ablasyonunda 6 $\mathrm{mm}$ ve $8 \mathrm{~mm}$ kriyokateterlerin karşılaştırıldığı geniş kapsamlı çalışmalarında, her iki kateterle akut başarı oranının $\% 100$, nüks oranının benzer olduğunu $(6 \mathrm{~mm}$ ile \%9,6; 8 mm ile \%8) bildirmişlerdir. AVNRT'li hastalarda RF ve KRA sonuçlarının karşılaştırıldığı bir metaanalizde ise nüks oranının kriyoblasyonda daha yüksek olduğu ancak özellikle çocuk ve genç yaştaki hastalarda AV blok riski açısından kriyoaablasyon yeğlenmesi gerektiği sonucuna varılmıştı ${ }^{31}$. Bu çalışmanın aksine, Karacan ve ark. ${ }^{32}$, yaptıkları ve toplam AVNRT'li 275 hastayı içeren geniş kapsamlı çalışmalarında, tüm hastalarda Ensite NavX Sistem ile $6 \mathrm{~mm}$ veya $8 \mathrm{~mm}$ uçlu kateter ile KRA yaptıklarını ve hastalarında akut başarı oranınının $\% 100$, nüks oranını ise $\% 4.4$ olduğunu bildirmişlerdir. Yukarıda söz edilen metanalizde kriyolezyon sayısının ve süresinin Karacan ve ark. ${ }^{32}$ yaptıkları çalışmadan daha az olması nedeniyle nüks oranları yüksek olabilir. Tanidir ve ark. ${ }^{33}$ da sağ taraflı AP'li hastalarda $8 \mathrm{~mm}$ uçlu kriyokateterin hastalarda başarılı ve güvenli olarak kullanılabileceğini bildirmişlerdir. Çalışmamızda, hastalarımızın 34'ünde KRA ve 14'üne RFA uygulandı. Akut başarı oranımız $\% 95,8$, nüks oranımız 6,2 idi.

Sonuç olarak, çalışmamızda çocuklarda 3-D elektroanatomik haritalama eşliğinde SVT ablasyonunun güvenlik ve etkinlikten ödün vermeden yüksek başarı ve düşük komplikasyon oranlarıyla uygulanabildiği gösterilmiştir. Çalışmamızın en önemli özelliklerinden birisi, hastalarımızın büyük çoğunluğunda floroskopi kullanılmamış olmasıdır. Literatürde, çocuklarda SVT ablasyonunda sınırlı floroskopik yaklaşım ile ilgili çaIışma sayısı oldukça azdır. Çocuklarda konvansiyonel 2-D yöntemlerle X-ışını kullanılarak yapılan elektrofizyolojik çalışma ve ablasyon işlemlerinde hem aritmojenik odağın yerinin tam tespiti her zaman olası olmamakta hem de hasta ve işlemi yapan personeli uzun dönemde yüksek düzeyde radyasyona maruz kalmaktadır. Bu nedenle 3-D elektroanatomik haritalama yöntemi ile işlem başarısının belirgin oranda arttırılması, işlem süresinin kısaltılması ve radyasyon maruziyetinin belirgin olarak azaltılıp hatta bazı işlemlerde tamamen ortadan kaldırılması sağlanacaktır. Buna ek olarak, AVNRT ablasyonlarında veya AV nod ya da his demetine yakın AP ablasyonlarında KRA uygulamasının AV tam blok riski olmadan yüksek başarı ile uygulanabilmesi nedeniyle bu hastalarda KRA yeğlenmelidir.

\section{KAYNAKLAR}

1. Salerno JC, Seslar SP, Chun TU, et al. Predictors of ECMO support in infants with tachycardia-induced cardiomyopathy. Pediatr Cardiol. 2011;32:754-8. https://doi.org/10.1007/s00246-011-9961-4

2. Ko JK, Deal BJ, Strasburger JF, Benson DW, Jr. Supraventricular tachycardia mechanisms and their age distribution in pediatric patients. Am J Cardiol. 1992;69:1028-32. https://doi.org/10.1016/0002-9149(92)90858-V

3. Nadas AS, Daeschner CW, Roth A, Blumenthal SL. Paroxysmal tachycardia in infants and children; study of 41 cases. Pediatrics. 1952;9:167-81.

4. Perry JC, Garson A, Jr. Supraventricular tachycardia due to Wolff-Parkinson-White syndrome in children: early disappearance and late recurrence. J Am Coll Cardiol. 1990;16:121520. https://doi.org/10.1016/0735-1097(90)90555-4

5. Thomas PE, Macicek SL. Catheter ablation to treat supraventricular arrhythmia in children and adults with congenital heart disease: What We Know and Where We Are Going. Ochsner J. 2016;16:290-6.

6. Calkins $\mathrm{H}$, Yong P, Miller JM, et al. Catheter ablation of accessory pathways, atrioventricular nodal reentrant tachycardia, and the atrioventricular junction: final results of a prospective, multicenter clinical trial. The Atakr Multicenter Investigators Group. Circulation. 1999;99:262-70.

https://doi.org/10.1161/01.CIR.99.2.262

7. Calkins H, Niklason L, Sousa J, et al. Radiation exposure during radiofrequency catheter ablation of accessory atrioventricular connections. Circulation. 1991;84:2376-82. https://doi.org/10.1161/01.CIR.84.6.2376 
8. Perisinakis K, Damilakis J, Theocharopoulos N, et al. Accurate assessment of patient effective radiation dose and associated detriment risk from radiofrequency catheter ablation procedures. Circulation. 2001;104:58-62. https://doi.org/10.1161/hc2601.091710

9. Clay MA, Campbell RM, Strieper M, et al. Long-term risk of fatal malignancy following pediatric radiofrequency ablation. Am J Cardiol. 2008;102:913-5. https://doi.org/10.1016/j.amjcard.2008.05.033

10. Swissa M, Birk E, Dagan T, et al. Radiofrequency catheter ablation of atrioventricular node reentrant tachycardia in children with limited fluoroscopy. Int J Cardiol. 2017;236:198202.

https://doi.org/10.1016/j.ijcard.2017.01.128

11. Ergul Y, Tola HT, Kiplapinar N, et al. Cryoablation of anteroseptal accessory pathways in children with limited fluoroscopy exposure. Pediatr Cardiol. 2013;34:802-8. https://doi.org/10.1007/s00246-012-0536-9

12. Ergul Y, Akdeniz C, Kiplapinar N, Tuzcu V. Successful cryoablation of Mahaim tachycardia in a child with Ebstein's anomaly. Pediatr Cardiol. 2013;34:1890-5.

https://doi.org/10.1007/s00246-012-0434-1

13. Buddhe S, Singh H, Du W, Karpawich PP. Radiofrequency and cryoablation therapies for supraventricular arrhythmias in the young: five-year review of efficacies. Pacing Clin Electrophysiol. 2012;35:711-7. https://doi.org/10.1111/j.1540-8159.2012.03372.x

14. Van Hare GF, Javitz $H$, Carmelli D, et al. Prospective assessment after pediatric cardiac ablation: demographics, medical profiles, and initial outcomes. J Cardiovasc Electrophysiol. 2004;15:759-70. https://doi.org/10.1046/j.1540-8167.2004.03645.x

15. Rodriguez LM, Leunissen J, Hoekstra A, et al. Transvenous cold mapping and cryoablation of the AV node in dogs: observations of chronic lesions and comparison to those obtained using radiofrequency ablation. J Cardiovasc Electrophysiol. 1998;9:1055-61. https://doi.org/10.1111/j.1540-8167.1998.tb00883.x

16. Khairy P, Chauvet $P$, Lehmann J, et al. Lower incidence of thrombus formation with cryoenergy versus radiofrequency catheter ablation. Circulation. 2003;107:2045-50. https://doi.org/10.1161/01.CIR.0000058706.82623.A1

17. Tuzcu V. Significant reduction of fluoroscopy in pediatric catheter ablation procedures: long-term experience from a single center. Pacing Clin Electrophysiol. 2012;35:1067-73. https://doi.org/10.1111/j.1540-8159.2012.03472.x

18. Smith G, Clark JM. Elimination of fluoroscopy use in a pediatric electrophysiology laboratory utilizing three-dimensional mapping. Pacing Clin Electrophysiol. 2007;30:510-8. https://doi.org/10.1111/j.1540-8159.2007.00701.x

19. Haissaguerre M, Gaita F, Marcus FI, Clementy J. Radiofrequency catheter ablation of accessory pathways: a contemporary review. J Cardiovasc Electrophysiol. 1994;5:532-52. https://doi.org/10.1111/j.1540-8167.1994.tb01293.x

20. Bastani $H$, Insulander $P$, Schwieler J, et al. Cryoablation of superoparaseptal and septal accessory pathways: a single centre experience. Europace. 2010;12:972-7. https://doi.org/10.1093/europace/euq079

21. Hindricks G. The Multicentre European Radiofrequency Survey (MERFS): complications of radiofrequency catheter ablation of arrhythmias. The Multicentre European Radiofrequency Survey (MERFS) investigators of the Working Group on Arrhythmias of the European Society of Cardiology. Eur Heart J. 1993;14:1644-53. https://doi.org/10.1093/eurheartj/14.12.1644

22. de Sisti A, Tonet J. Cryoablation of atrioventricular nodal reentrant tachycardia: a clinical review. Pacing Clin Electrophysiol. 2012;35:233-40. https://doi.org/10.1111/j.1540-8159.2011.03244.x

23. Deisenhofer I, Zrenner B, Yin YH, et al. Cryoablation versus radiofrequency energy for the ablation of atrioventricular nodal reentrant tachycardia (the CYRANO Study): results from a large multicenter prospective randomized trial. Circulation. 2010;122:2239-45. https://doi.org/10.1161/CIRCULATIONAHA.110.970350

24. Collins KK, Dubin AM, Chiesa NA, Avasarala K, Van Hare GF. Cryoablation versus radiofrequency ablation for treatment of pediatric atrioventricular nodal reentrant tachycardia: initial experience with 4-mm cryocatheter. Heart Rhythm. 2006;3:564-70.

https://doi.org/10.1016/j.hrthm.2006.01.026

25. Chan NY, Mok NS, Choy CC, et al. Treatment of atrioventricular nodal re-entrant tachycardia by cryoablation with an 8-mm-tip catheter versus radiofrequency ablation. J Interv Card Electrophysiol. 2012;34:295-301. https://doi.org/10.1007/s10840-012-9670-9

26. Chan NY, Choy CC, Lau CL, et al. Cryoablation versus radiofrequency ablation for atrioventricular nodal reentrant tachycardia: patient pain perception and operator stress. Pacing Clin Electrophysiol. 2011;34:2-7. https://doi.org/10.1111/j.1540-8159.2010.02858.x

27. Das $\mathrm{S}$, Law IH, Von Bergen $\mathrm{NH}$, et al. Cryoablation therapy for atrioventricular nodal reentrant tachycardia in children: a multicenter experience of efficacy. Pediatr Cardiol. 2012;33:1147-53. https://doi.org/10.1007/s00246-012-0273-0

28. Chanani NK, Chiesa NA, Dubin AM, et al. Cryoablation for atrioventricular nodal reentrant tachycardia in young patients: predictors of recurrence. Pacing Clin Electrophysiol. 2008;31:1152-9. https://doi.org/10.1111/j.1540-8159.2008.01156.x

29. McDaniel GM, Van Hare GF. Catheter ablation in children and adolescents. Heart Rhythm. 2006;3:95-101. https://doi.org/10.1016/j.hrthm.2005.09.028

30. Tuzcu V, Gul EE, Karacan M, et al. Comparison of 6-mm Versus 8-mm-Tip cryoablation catheter for the treatment of atrioventricular nodal reentrant tachycardia in children: A Prospective Study. Pediatr Cardiol. 2017;38:1220-5. https://doi.org/10.1007/s00246-017-1648-z

31. Hanninen M, Yeung-Lai-Wah N, Massel D, et al. Cryoablation versus RF ablation for AVNRT: A meta-analysis and systematic review. J Cardiovasc Electrophysiol. 2013;24:1354-60. https://doi.org/10.1111/jce.12247

32. Karacan M, Celik N, Akdeniz C, Tuzcu V. Long-term outcomes following cryoablation of atrioventricular nodal reentrant tachycardia in children. Pacing Clin Electrophysiol. 2018;41:255-60. https://doi.org/10.1111/pace.13277

33. Tanidir IC, Ergul Y, Ozturk E, et al. Cryoablation with an 8-mmTip Catheter for Right-Sided Accessory Pathways in Children. Pacing Clin Electrophysiol. 2016;39:797-804. https://doi.org/10.1111/pace.12892 